\section{ULTRASONOGRAPHY: current status, challenges, and future directions}

\author{
BYUNG IHN CHOI
}

Honorary Editor

ULTRASONOGRAPHY

Since Ultrasonography was launched as an international peer-reviewed academic journal dedicated to medical ultrasound (US) in January 2014, it has been an honor and privilege for me to serve as the journal's Honorary Editor [1]. The purpose of this editorial update is to provide readers with some recent information and to share my views on the journal and its future directions.

During the last 4 years, Ultrasonography has published a total of 160 peer-reviewed articles. In 2017, the Ultrasonography home page had over 85,000 hits per month, with over 2,300 downloads of manuscripts from 115 different countries per month. In 2016, Ultrasonography demonstrated an increase in the number of citations by authors throughout the world, and the estimated impact factor of Ultrasonography reached 2.075 [2], as it has continued to attract more and more international readers. Consequently, Ultrasonography became indexed by the Web of Science's new Emerging Source Citation Index (ESCI) in November 2016 [2] and by SCOPUS in September 2017, marking it as one of the leading global journals in the field of medical US.

The aim of Ultrasonography is to provide up-to-date information on new diagnostic concepts and technical developments, as well as to publish well-designed reviews of contemporary issues in patient care in the field of medical US. As the Honorary Editor of Ultrasonography, I am aware of the editor's tremendous responsibility in guiding the publication to fulfill the aims of Ultrasonography and of how important the roles of the authors, reviewers, and readers are for a journal to be successful.

Those of us who are involved in the journal's publication have the great responsibility to provide an effective means to disseminate the original work of the authors as well as to provide timely, high-quality research to readers. We will continue to promote and publish high-quality peer-reviewed research. We also plan to invite internationally renowned scholars to submit reviews of the latest research and introductions to innovative new technologies to enhance the quality of the content and to attract a larger international readership. Original articles that advance the science of US will remain the centerpiece of the journal, while

Byung Ihn Choi, MD

Department of Radiology, Chung-Ang University Hospital, 102 Heukseok-ro, Dongjak-gu, Seoul 06973, Korea Tel. +82-2-3299-3204, Fax. +82-2-6299-2064, E-mail: bichoi@caumc.or.kr

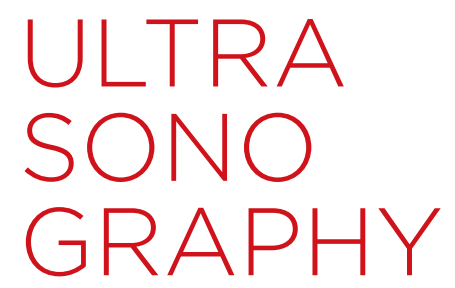

EDITORIAL

https://doi.org/10.14366/usg. 17069 pISSN: 2288-5919 - elSSN: 2288-5943

Ultrasonography 2018;37:1-2

Received: November 2, 2017

Revised: November 22, 2017

Accepted: November 23, 2017
This is an Open Access article distributed under the terms of the Creative Commons Attribution NonCommercial License (http://creativecommons.org/ licenses/by-nc/3.0/) which permits unrestricted noncommercial use, distribution, and reproduction in any medium, provided the original work is properly cited.

Copyright $(2018$ Korean Society of Ultrasound in Medicine (KSUM)

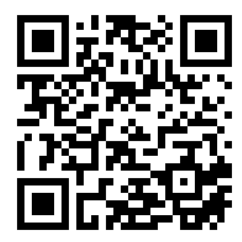

How to cite this article:

Choi BI. ULTRASONOGRAPHY: current status, challenges, and future directions. Ultrasonography. 2018 Jan;37(1):1-2. 
Pictorial Essays, Technical Notes, and Perspectives will continue to be published. Sonologists and US-related specialists are encouraged to submit their most promising research results to Ultrasonography. We will continue to provide high-quality editing and publishing services without cost, and there will be no fees for submissions or for the publication process.

A quality publication must have capable, fair, and considerate reviewers, as well as outstanding authors and manuscripts. The adoption of a double-blind peer review process and an open-access policy will enable Ultrasonography to fulfill its obligation to publication ethics; each article must also comply with our editorial standards for quality and ethics. We have thus established an Editorial Board composed of internationally renowned scholars and scientists to meet global standards for the process of peer-reviewing submitted manuscripts. We are grateful to the many reviewers and editorial members who volunteer their time and effort to ensure the quality of the journal's content. The speed of publication is also important for the journal's success. We have established a state-of-the-art electronic manuscript submission, review, and electronic publishing system, and we make our best effort to complete the review process as soon as possible, ideally within 4 weeks of receiving a manuscript submission.

Going forward, I believe Ultrasonography will be a useful and valuable international journal covering recent advances in US for every US-related specialist. I look forward to receiving a wide range of submissions and contributions from basic and clinical researchers throughout the world.

ORCID: Byung Ihn Choi: http://orcid.org/0000-0002-5613-1881

\section{References}

1. YU JS. ULTRASONOGRAPHY: a new beginning with international open access. Ultrasonography 2014;33:1.

2. Yu JS. ULTRASONOGRAPHY: two years of globalization and the achievement of ESCl status. Ultrasonography 2016;35:1-2. 